\title{
From Upstream to Purification: Production of Lactic Acid from the Organic Fraction of Municipal Solid Waste
}

\author{
José Pablo López-Gómez ${ }^{1}$ Peter Unger ${ }^{1} \cdot$ Roland Schneider $^{1} \cdot$ Joachim Venus $^{1}$
}

Received: 30 October 2019 / Accepted: 23 February 2020 / Published online: 28 February 2020

(c) The Author(s) 2020

\begin{abstract}
The implementation of an efficient and sustainable management of the organic fraction of municipal solid wastes (OFMSW) is a topic of intensive discussion in EU countries. Recently, the OFMSW has been investigated as a potential substrate for the production of lactic acid (LA) through fermentation. Nevertheless, none of the reports available in the literature covers all the stages of the conversion process. The present research article is a comprehensive study which includes the upstream, fermentation and downstream for the conversion of OFMSW into LA. Several batches of OFMSW were analysed for the evaluation of sugars released and LA content before the fermentation. Fermentations were performed to study the effect of hydrolysate quality on the LA production using Bacillus coagulans A166. Purification of LA, based on electrodialysis, was carried out after pilot scale fermentation of OFMSW hydrolysates. Results showed that variations in the concentrations of sugars and LA are observed from batch to batch of OFMSW. More specifically, LA can reach high concentrations even before the substrates are hydrolysed, limiting the potential applications of the final product due to low enantiomeric purities. In general, fermentations of the hydrolysate were efficient, with conversion yields of $0.65 \mathrm{~g} \mathrm{~g}^{-1}$ without the addition of extra nutrients. Downstream is still a challenging stage of the process. A LA recovery of 55\% was obtained, with the most significant losses observed during the micro- and nanofiltrations. Overall, a conversion of 10\% from OFMSW substrate (dry basis) to LA was achieved.
\end{abstract}

\section{Graphic Abstract}

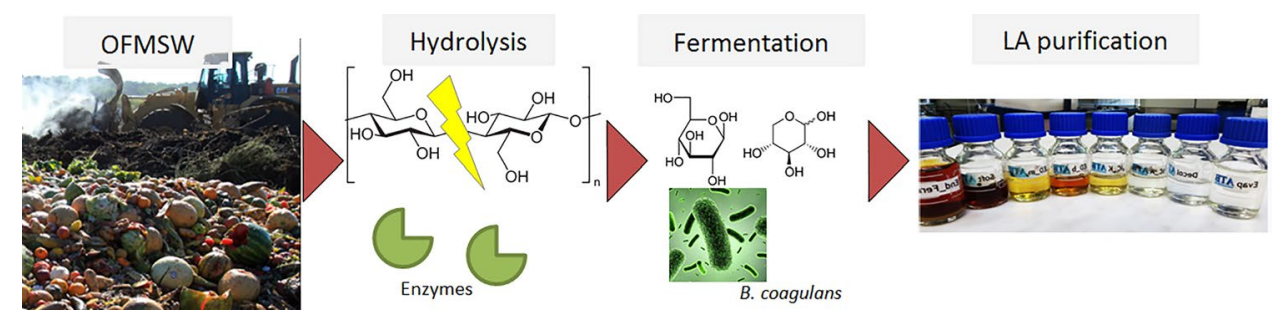

Keywords Lactic acid · Purification · Enzymatic hydrolysis · Bacillus coagulans $\cdot$ Electrodialysis · Pilot scale

\section{Statement of Novelty}

Although there has been a lot of attention regarding the bioconversion of the organic fraction of municipal solid waste (OFMSW) into energy (biogas), research involving

José Pablo López-Gómez

plopezgomez@atb-potsdam.de

1 Leibniz Institute for Agricultural Engineering and Bioeconomy, Max-Eyth-Allee 100, Potsdam, Germany the production of lactic acid (LA) from OFMSW has been very limited. Nevertheless, the chemical composition of this material, rich in carbohydrates and proteins, makes it a great substrate for fermentation processes. This study involves the hydrolysis of the OFMSW and the evaluation of how the quality of different batches can impact the final enantiomeric purity of the product, the fermentation stage and also the purification steps. The article includes experimental results from the hydrolysis, fermentation and purification until a final highly pure LA solution was obtained, providing a 
comprehensive overview of the full process, from upstream to purification.

\section{Introduction}

The implementation of an efficient and sustainable management of the organic fraction of municipal solid wastes (OFMSW) is a topic of intensive discussion in EU countries. Over the last two decades, EU efforts have focused on waste prevention, recycling and recovery [1]. Most commonly, OFMSW are used for the production of energy by incineration or biological treatment through biogas or compost production $[2,3]$. Even though these practices have significantly decreased the amount of waste sent to landfills, they fail to meet the sustainability standards of the EU, which target a complete exploitation of waste streams for the production of value-added products [1].

The large majority of the work regarding the treatment and upgrading of OFMSW has been directed towards the production of biogas as a source of bioenergy, with relative success [4]. However, more recently, alternatives have been explored to find another product with higher value in the market with various attempts reported in the literature, including volatile fatty acids, hydrogen, ethanol and butanol [5-7]. Recently, the OFMSW has also been investigated as a potential substrate for the production of LA in fermentations [8-11]. Most of the OFMSW is derived from food residues from households and restaurants and it is constituted mainly by carbohydrates, proteins and fats [12]. Nonetheless, in order to improve microbial conversions, the complex carbohydrate fraction needs to be first broken down i.e. hydrolysed, a step which has been established as the most significant part in the biogas production process [13].

To the best of the authors' knowledge, there are no reports available in the literature that explore the whole production process from OFMSW to LA. It has been shown that OFMSW can be a good substrate for LA production in naturally occurring fermentations $[10,11]$ and its potential in controlled fermentations has also been previously demonstrated [8]. However, there are still important questions involving the feasibility of a process involving the conversion of OFMSW into LA. Critically, the evaluation of potential variations in the composition of OFMSW hydrolysates, in terms of sugars production and initial LA concentration, needs to be addressed. As shown by Probst et al. [14], the natural occurring LA bacteria of the OFMSW can increase the content of LA even before the hydrolysis takes place. These LA bacteria generate a racemic mixture of dextro(D-) and levo- (L-) LA which decreases the final enantiomeric purity of the product after the fermentations. High enantiomeric purities are of upmost importance for specialised applications such as in the production of polylactic acid (PLA). The purification of LA is another particularly challenging issue when alternative and low-cost substrates, which typically have a very complex physical and chemical composition, are used [15]. Carrying out studies that showcase the production of any metabolite until its purification stages provides a better overview of the whole process, allowing for a greater understanding of its strengths and limitations.

The present research article is a comprehensive study which includes the upstream, fermentation and downstream for the conversion of OFMSW into LA. Several batches of OFMSW were analysed for the evaluation of sugars released and LA content before the fermentation. Following that, a couple of fermentations are shown to illustrate the effect that hydrolysate quality can have on the growth of bacteria and the production of LA. Downstream and purification of LA was carried out after a pilot scale fermentation of OFMSW hydrolysates. The LA purification, based on electrodialysis, involves several steps which impact the overall performance of the process. Thus, the manuscript aims to provide the reader with an overview of the whole production process, with special emphasis in major challenges in the bioconversion of OFMSW into LA.

\section{Methods}

\section{Substrate and Hydrolysis}

OFMSW samples, kindly provided by IMECAL SA company (L’Alcúdia, Valencia, Spain), were obtained from a municipal solid waste treatment plant located in Valencia, Spain. Before the homogenisation of the samples, they were screened for the removal of inert materials such as stones, plastic, glass, etc. The samples were homogenised with a hammer mill and after that sterilised in an autoclave at $121{ }^{\circ} \mathrm{C}$ for $1 \mathrm{~h}$. After sterilisation, the samples were kept at $-20{ }^{\circ} \mathrm{C}$ until used.

Hydrolyses were performed at different scales, in 3, 5 or $50 \mathrm{~L}$ reactors with a solids load of $20 \% \mathrm{w} \mathrm{w}^{-1}$ for all the cases. Temperature for hydrolysis was $50{ }^{\circ} \mathrm{C}$ with $150 \mathrm{rpm}$ of stirring and a $\mathrm{pH}$ of 5 , controlled by the addition of $\mathrm{NaOH}$ $\left(20 \% \mathrm{w} \mathrm{w}^{-1}\right)$. The enzymatic cocktail used was Cellic CTec2 (Novozymes A/S, Basgsværd, Denmark), a cellulose complex for the degradation of cellulose into fermentable sugars. The enzyme mixture was added at $1 \%\left(\mathrm{v} \mathrm{v}^{-1}\right)$. Samples were taken during the hydrolysis to quantify the formation of sugars and the variation in LA concentration.

\section{Microorganisms and Inoculum}

The strain used for the fermentations was Bacillus coagulans A166. This L-LA producer was obtained from the Leibniz 
Institute for Agricultural Engineering and Bioeconomy (ATB) in Potsdam, Germany. Pre-cultures for the fermentations were carried out in $250 \mathrm{~mL}$ shake flasks containing $60 \mathrm{~mL}$ of de Man, Rogosa and Sharpe (MRS) broth (Merck, Germany) and dolomite EVERZIT Dol 0.5-2.5 mm (Evers, Germany). After inoculation, the flasks were incubated in at $150 \mathrm{rpm}$ and $52{ }^{\circ} \mathrm{C}$ for $12-16 \mathrm{~h}$.

\section{Fermentations}

Fermentations were carried out consecutively after hydrolyses. Laboratory scale fermentations were carried out in 5 L BIOSTAT bioreactors (Sartorius AG, Germany) with a working volume of $3 \mathrm{~L}$. The fermentations were carried out at $52{ }^{\circ} \mathrm{C}, 200 \mathrm{rpm}$ and a pH of 6.0 controlled by the addition of $\mathrm{NaOH} 20 \%\left(\mathrm{w} \mathrm{v}^{-1}\right)$. Samples were taken regularly for the quantification of sugars and LA.

Pilot scale fermentation was performed to study the purification of LA from the OFMSW. It was done in a $72 \mathrm{~L}$ BIOSTAT UD bioreactor (B-Braun Biotech, Germany) with 33.5 L of OFMSW hydrolysate. The pre-culture for this fermentation was prepared in a 1 L BIOSTAT bioreactor (Sartorius AG, Germany) with $700 \mathrm{~mL}$ working volume of the same hydrolysate medium. Conditions for the fermentation was as in the lab scale experiments $\left(52{ }^{\circ} \mathrm{C}, 200 \mathrm{rpm}, \mathrm{pH}\right.$ 6). Samples were taken regularly for the quantification of sugars and LA.

\section{Downstream and Purification}

Following the pilot scale fermentation, a LA purification process based on electrodialysis was carried out. After the inactivation of the fermentation broth (at $95{ }^{\circ} \mathrm{C}$ for $20 \mathrm{~min}$ ), microfiltration was carried out with a cross-flow micro-filtration system (UFI-TEC, Germany), pore size $0.2 \mu \mathrm{m}$, at 1.5 bar and $5{ }^{\circ} \mathrm{C}$, equipped with 4 TAMI membranes (TAMI Industries, France). The nanofiltration was performed (150-300 Da cut-off) at 30 bar with an UFI-TEC crossflow nanofiltration system (UFI-TEC, Germany) followed by softening of the broth in a column packed with a PUROLITE S950 acid chelating resin (Purolite, Germany). After that, the electrodialysis was carried out in 2 steps using 11 cation and 10 anion exchange membranes Type II (Fujifilm, The Netherlands). The monopolar step ( $i$ ) was finished when the conductivity of the filtrate was below $1 \mathrm{mS} \mathrm{cm}{ }^{2}$, whereas the bipolar step ( $j$ ) was stopped when the conductivity of the filtrate was below $2 \mathrm{mS} \mathrm{cm}$. The concentrated LA stream was then passed through an adsorbent resin MACRONET ${ }^{\mathrm{TM}}$ MN-502 (Purolite, Germany) for decolourisation. Then, ion exchange chromatography was performed using resins RELITE EXA 133 (removal of cations) and RELITE EXC 08 (removal of ions) (Resindion S. R. L., Italy). Lastly, excess of water was eliminated by vacuum distillation at $55^{\circ} \mathrm{C},-1$ bar and $350 \mathrm{rpm}$ (Büchi Labortechnik, Germany). Neu et al. [16] provide a more detailed description of the downstream process.

\section{Analytical Assays}

During the hydrolyses and fermentations, quantification of sugars and LA was carried out via HPLC (Dionex, USA) with a Eurokat H column $(300 \mathrm{~mm} \times 8 \mathrm{~mm} \times 10 \mu \mathrm{m}$, Knauer, Germany) coupled with a refractive index detector (RI-71, Shodex, Japan). A solution of $5 \mathrm{mM} \mathrm{H}_{2} \mathrm{SO}_{4}$ was the mobile phase at a flow rate of $0.8 \mathrm{~mL} \mathrm{~min}^{-1}$. Likewise, optical purity of the samples was performed via HPLC (Dionex, USA) with a Phenomenex Chirex 3126 column $(150 \times 4.6 \mathrm{~mm} \mathrm{ID}$, Phenomenex, USA) at $30{ }^{\circ} \mathrm{C}$ coupled to an ultraviolet detector and $\mathrm{Cu}_{2} \mathrm{SO}_{4}$ flowing at $1 \mathrm{~mL} \mathrm{~min}^{-1}$ as the mobile phase. Quantifications of sugars, LA concentration and LA enantiomeric purity were carried out as detailed in Alexandri et al. [17]. A complete description of the methods for the ions and total nitrogen measurements can be found in Neu et al. [16].

\section{Results}

\section{Variation in the Concentration of Total Sugars and LA in OFMSW Hydrolysates}

OFMSW comprises a complex mixture of residues which can vary due to regional, seasonal and even socioeconomic factors [13]. Such variations can result in considerable changes in the composition of carbohydrates available for fermentation. Additionally, as explained by Probst et al. [14], the OFMSW is an ideal substrate for the proliferation of lactic acid bacteria (LAB). As shown by the authors, natural growth of $L A B$ can occur within a wide range of temperatures and $\mathrm{pH}$. This endemic production of LA is crucial since the indigenous bacteria produce racemic mixtures of D- and L-LA [10]. Because an effective separation of the enantiomers is still not feasible, the enantiomeric mixture will remain throughout the process, reducing final optical purities. Depending on the final application of LA, as for the case of PLA production, very high optical purities are necessary to improve the mechanical and thermal properties of the product [18]. Therefore, in some cases, a high initial LA concentrations in the OFMSW could be detrimental.

Twenty-three OFMSW hydrolysate batches were obtained during different times of the year and the analysis of sugars and LA is presented in Fig. 1. The first batches were prepared during the winter months and production continued until summer. As seen, considerable variations occurred amongst the samples, with total sugar concentration ranging from 86.5 to only $36.6 \mathrm{~g} \mathrm{~L}^{-1}$. LA was present in every batch produced, with concentrations ranging from 6.8 to $34.4 \mathrm{~g}$ 


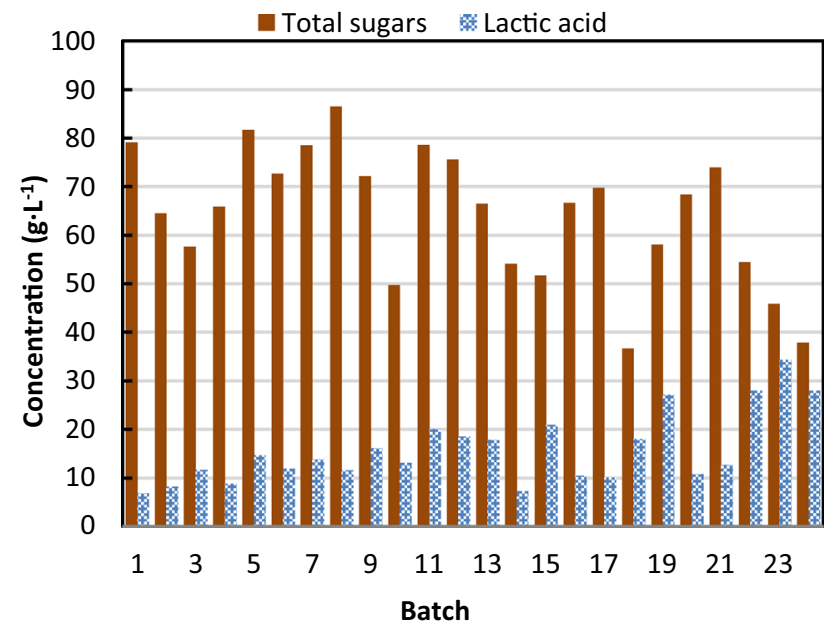

Fig. 1 Variation in the concentration of total sugars and lactic acid of 24 OFMSW hydrolysates

$\mathrm{L}^{-1}$. There is an apparent relationship between time of the year when the sample was obtained and the LA concentration. Most likely, the warmer summer temperatures created a more suitable environment for the growth of LAB before the hydrolysis which explains the increasing tendency in LA concentration in the samples.

On average, the concentrations of total sugars and LA were 63.2 and $16.8 \mathrm{~g} \mathrm{~L}^{-1}$, respectively. As it would be expected, in most cases, a higher LA concentration was accompanied by a reduction in the concentration of total sugars. Naturally, a hydrolysate with lower concentrations of sugars and high LA content would result in fermentation broths with reduced optical purities in comparison to a hydrolysate with high sugar and low LA content. Thus, without variations in the OFMSW collection system the scope for applications of the process would be limited by the initial LA content of the samples.

\section{Hydrolyses and Subsequent Fermentations of OFMSW}

Sequential hydrolyses and fermentations were carried out with two separate OFMSW batches. The first batch was from a sample collected during March of 2019 and the second sample was collected during June of the same year. Figure 2 shows the two phases of the process for the first batch (total time $126 \mathrm{~h}$ ), the hydrolysis from 0 to $72 \mathrm{~h}$ and the fermentation from 72 to $126 \mathrm{~h}$.

As seen, a rapid increase in the concentration of total sugars could be observed during the first $24 \mathrm{~h}$ of hydrolysis. The increase was mainly due to the release of glucose with only marginal contributions from other sugars such as xylose. At $72 \mathrm{~h}$ of hydrolysis, the free sugars concentration had almost doubled, going from 37 to $66 \mathrm{~g} \mathrm{~L}^{-1}$. Remarkably,

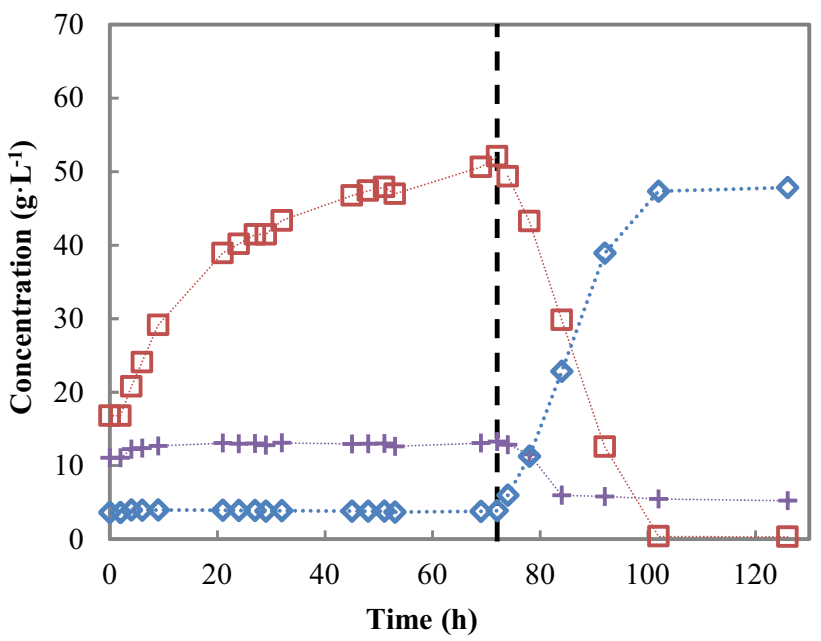

Fig. 2 Hydrolysis and subsequent fermentation of OFMSW. The black vertical line at $72 \mathrm{~h}$ marks the inoculation and start of the fermentation. The graph shows the variation in the concentration of glucose (square), xylose (plus) and lactic acid (diamond)

the concentration of LA remained constant throughout the hydrolysis.

Fermentations were carried out using the strain B. coagulans A166, experimental work regarding strain screening and selection can be found elsewhere [8]. Once inoculated, the fermentation of sugars occurred rapidly with a complete consumption of glucose at $28 \mathrm{~h}$ of fermentation. LA reached a final concentration of $47.3 \mathrm{~g} \mathrm{~L}^{-1}$ by the end of the process, an increase of $43.5 \mathrm{~g} \mathrm{~L}^{-1}$. The process was stopped after $126 \mathrm{~h}$, however, no significant variations were observed in the concentration of sugars after around $40 \mathrm{~h}$ of hydrolysis. Furthermore, production of LA ceased after $30 \mathrm{~h}$ of fermentation. Thus, an optimised experiment would last about $70 \mathrm{~h}$ (56 $\mathrm{h}$ less than the experiment shown in Fig. 2).

Figure 3 a shows the hydrolysis and fermentation of the OFMSW batch from June 2019 (total experimental time $117 \mathrm{~h}$ ). Initial LA concentration was considerably higher $\left(42 \mathrm{~g} \mathrm{~L}^{-1}\right)$ than the one from the previous experiment. As in the previous experiment, negligible variations were observed in LA concentration during hydrolysis. Consistently, the concentration of glucose only increased from 21 to $32 \mathrm{~g} \mathrm{~L}^{-1}$. Without a significant increase from 24 to $46 \mathrm{~h}$ in the concentration of glucose, it was decided to start the fermentation after 48 h. Similarly, the fermentation profile in Fig. 3a significantly differs from the one showed in Fig. 2. Although glucose was completely consumed, it took the strain about $52 \mathrm{~h}$ i.e. $22 \mathrm{~h}$ more than in the previous case (Fig. 2). A potential reason for the longer fermentation time could be the decrease in nutrients due to microbial activity before the hydrolysis. This was confirmed in a second experiment using the same OFMSW batch (Fig. 3b), in which proteases were added to the fermentation broth. Although hydrolysis 


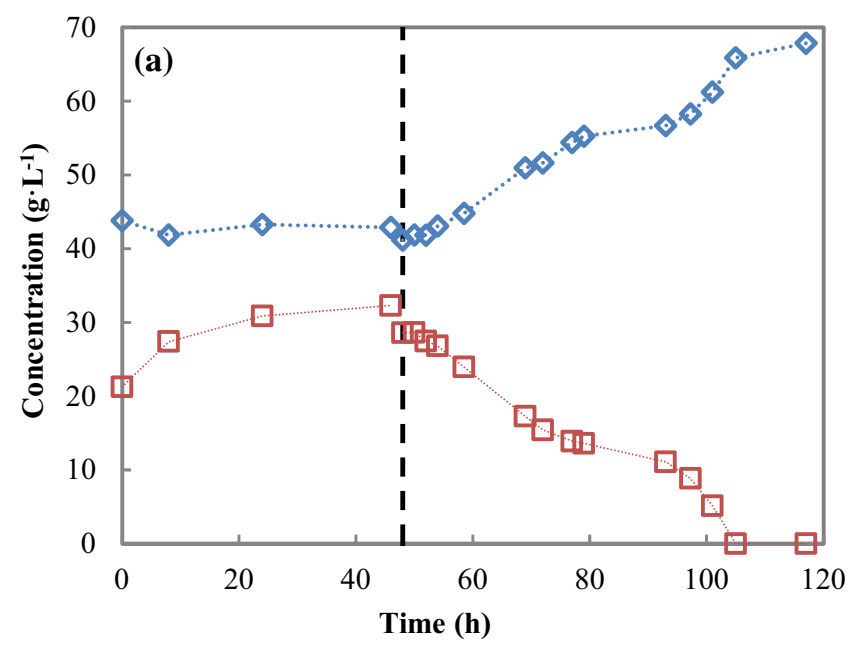

Fig. 3 a Hydrolysis and subsequent fermentation of OFMSW. The black vertical line at $48 \mathrm{~h}$ marks the inoculation and start of the fermentation. The graph shows the variation in the concentration of glu-

profiles were very similar in Fig. 3a and b, a drastic reduction of around $30 \mathrm{~h}$ in the fermentation time was observed in the experiment with proteases (total experimental time $71 \mathrm{~h}$ ). Nevertheless, as shown in Fig. 2 and also demonstrated by López-Gómez et al. [8], OFMSW hydrolysates can be good substrates for the growth of $B$. coagulans, even without the addition of any extra nutrients.

The batch from June yielded a higher LA concentration of approximately $68 \mathrm{~g} \mathrm{~L}^{-1}\left(47 \mathrm{~g} \mathrm{~L}^{-1}\right.$ in the batch from March). However, the difference was due to the initial LA present in the sample $\left(42.9 \mathrm{~g} \mathrm{~L}^{-1}\right)$ and not to the fermentation process. In fact, the concentration of LA increased only by approximately $25 \mathrm{~g} \mathrm{~L}^{-1}$, a much lower value than in the previous case in which LA concentration increased $43.5 \mathrm{~g} \mathrm{~L}^{-1}$. Most importantly, analysis for the L-LA enantiomeric purity showed values of $95.5 \%$ for the batch from March and only $70 \%$ for the batch from June. No variations in the concentrations of D-LA were observed throughout the process, which was expected since B. coagulans is a homofermentative $\mathrm{L}-$ LA producer.

\section{Lactic Acid Purification}

An important aspect in the LA production process, often neglected, is the downstream and purification. Probably, this is due to three reasons. The first one is that most of the research targets the utilisation of inexpensive raw materials which require intensive efforts for their pre-treatment and usually present many challenges during the fermentation step. Thus, unsurprisingly, a lot of work has been necessary in order to improve those stages of the processes. The second reason is that, typically, performing the purification requires large volumes of fermented broth. In many cases,

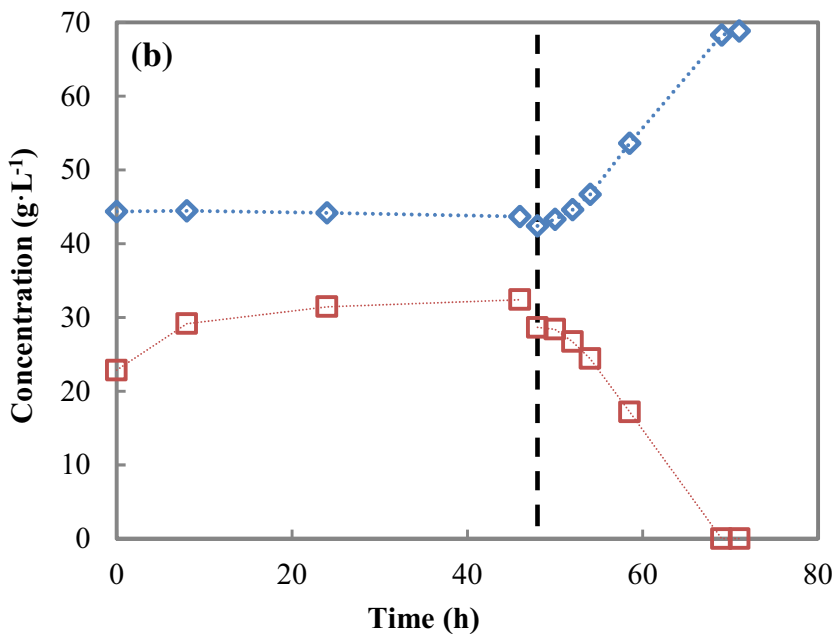

cose (square) and lactic acid (diamond). b Shows the hydrolysis and fermentation of the same substrate but with the addition of proteases for the fermentation step

most notoriously for lignocellulosic hydrolysates, producing large volumes of substrate for the fermentations can be challenging. Finally, downstream and purification require expensive equipment which are not available in many laboratories, halting the investigations. Therefore it is difficult to find studies covering both the upstream and downstream of LA production. Nonetheless, more recently, some studies and reviews dealing with downstream processing have been published [15, 19-21] and it is likely that this tendency will continue after the challenges in the pre-treatment and fermentation have been solved.

The most common LA separation method used in industry is based on the neutralisation and subsequent acidification of the fermentation broth. Firstly the broth is neutralised by the addition of $\mathrm{Ca}(\mathrm{OH})_{2}$ and, as a result, calcium lactate salt precipitates. After filtration, the salt is acidified with $\mathrm{H}_{2} \mathrm{SO}_{4}$ yielding $\mathrm{LA}$ and $\mathrm{CaSO}_{4}$. The latter, also known as gypsum, is generated in large quantities and pose environmental issues. An alternative method for the purification is based on a two-stage electrodialysis (ED) (monopolar and bipolar). Unlike the most common method, waste generation is kept to a minimum in this type of process. Purification of LA was performed by ED in order to get a better understanding of how this step could affect the overall yield of the process.

The fermentation broth used in the purification test was produced in a pilot scale fermentation with a total of $33.5 \mathrm{~L}$ working volume, the profile for the fermentation is shown in Fig. 4. The batch of OFMSW selected for this experiment had an initial LA concentration of $6.5 \mathrm{~g} \mathrm{~L}^{-1}$ and a relatively high sugars concentration with $51 \mathrm{~g} \mathrm{~L}^{-1}$ of glucose and $23.9 \mathrm{~g} \mathrm{~L}^{-1}$ of xylose. The fermentation time was $20 \mathrm{~h}$ and by the end LA had reached $60 \mathrm{~g} \mathrm{~L}^{-1}$ with an enantiomeric 


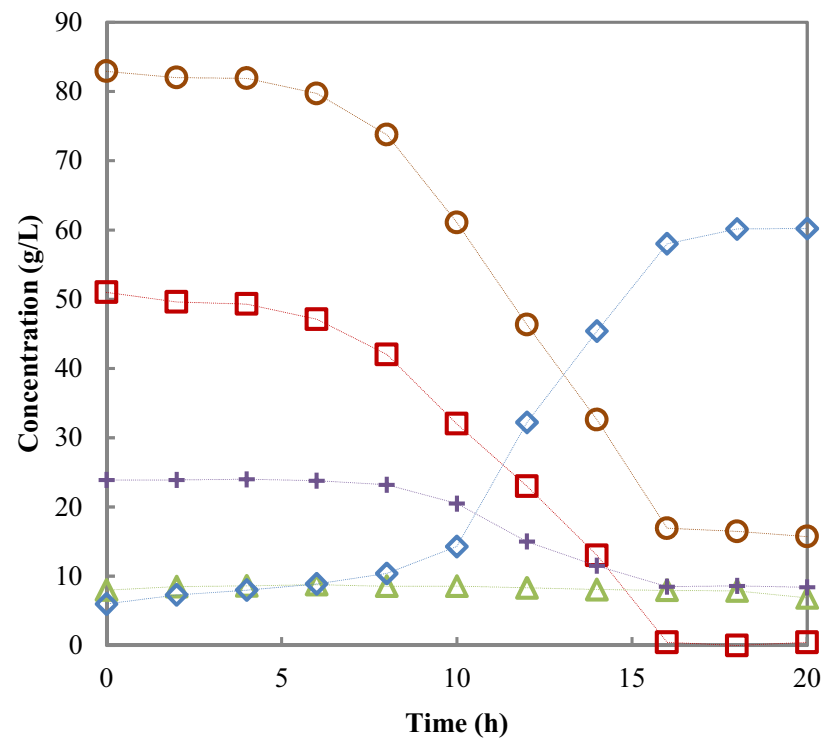

Fig. 4 Fermentations in the technical scale (33.5 L working volume) of the hydrolysate after microfiltration with $B$. coagulans A166. Variation in the concentration of total sugars (circle), glucose (square), disaccharides (triangle), xylose (plus) and lactic acid (diamond)

purity of $95.1 \%$ L-LA. Once more, the hydrolysate supported bacterial growth without the addition of any extra nutrients and without signs of inhibition. There were however residual sugars by the end of the fermentation $\left(15 \mathrm{~g} \mathrm{~L}^{-1}\right)$ consisting of xylose and disaccharides. Overall, the yield of LA from total sugars was $0.65 \mathrm{~g}_{\mathrm{LA}} \mathrm{g}_{\text {sugars. }}$.

After inactivation of the fermentation broth, the downstream and purification of LA took place. Figure 5 shows the diagram for the purification containing the additions, the residues from the units and the final volume in every step. The final volume of the fermentation was $35.6 \mathrm{~L}$ (due to base addition) with a LA concentration of $58.7 \mathrm{~g} \mathrm{~L}^{-1}$ and, by the end of the downstream, the product was $1.06 \mathrm{~L}$ of a solution containing $930 \mathrm{~g} \mathrm{~L}^{-1}$. Therefore, LA overall recovery yield was $45 \%$, a value comparable to previous reports in the literature that used organic and agricultural residues [16, 22]. In this case, most of the LA losses (about 60\%) were the result of the micro- and nanofiltration steps. A total of $311 \mathrm{~g}$, corresponding to $14.3 \%$ of the downstream losses, were lost during the microfiltration; whereas $335 \mathrm{~g} \mathrm{(15.5 \% )} \mathrm{were} \mathrm{lost}$ in the nanofiltration. These two steps are necessary for the preparation of the medium (by the removal of solids, residual sugars and proteins), to enter the ED, therefore, experimental work is required in order to improve their performance. After softening, with marginal losses, and monopolar ED with 5\% of total losses, bipolar ED was carried out with LA losses accounting for $10.5 \%$ of the total. In this step, two residual streams are produced. The first one is called base ED stream which contains a high concentration of sodium (used for the neutralisation of the fermentation). The volume

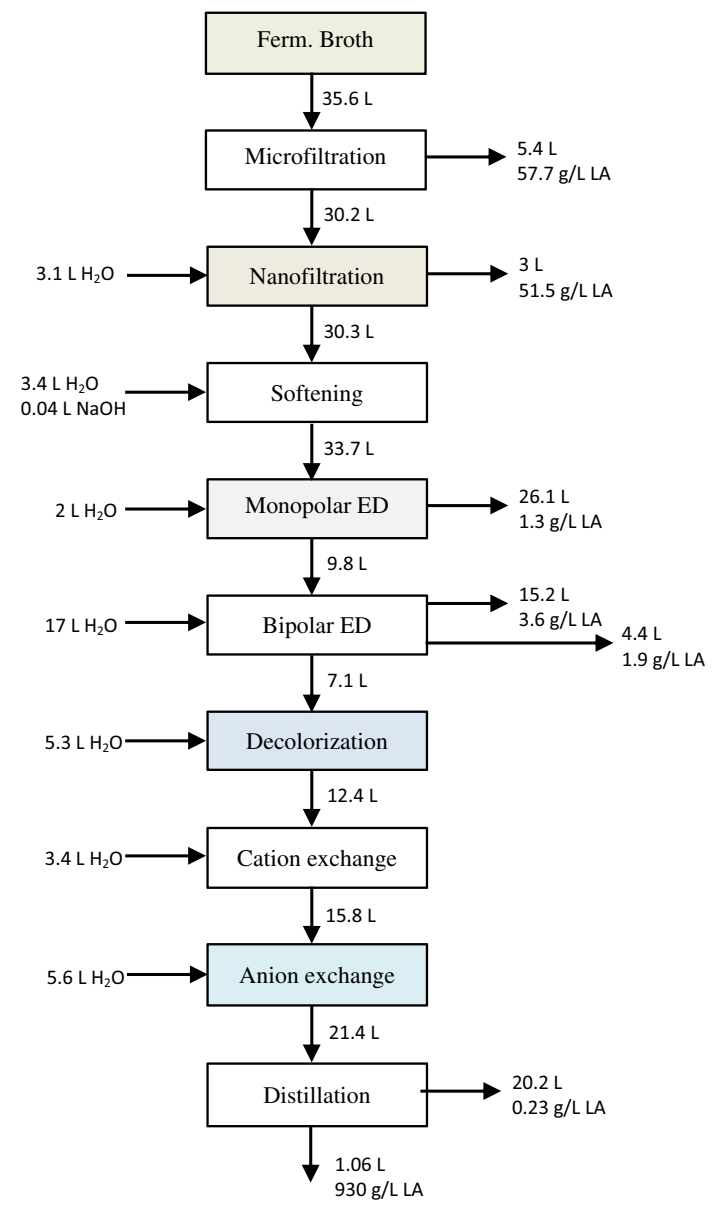

Fig. 5 Diagram of the LA purification steps

for that stream was $15.2 \mathrm{~L}$ and, in theory, it could be re-used for the neutralisation in further fermentations. Losses for the decolourization, cation- and anion exchange steps were 1, 4 and $14 \%$ of the total, respectively.

Figure 6 shows the variation in the concentration of ions, as well as the total volume at each step during the purification. As seen, a very high concentration of ions $\left(\mathrm{Cl}^{-}, \mathrm{Ca}^{2+}\right.$, $\mathrm{K}^{+}, \mathrm{Mg}^{+}, \mathrm{NH}_{4}{ }^{+}$and $\mathrm{SO}_{4}{ }^{2-}$ ) of around $5.5 \mathrm{~g} \mathrm{~L}^{-1}$ was present in the broth after fermentation. Additionally, as the result of neutralisation sodium was also present at a very high concentration (almost $10 \mathrm{~g} \mathrm{~L}^{-1}$ ). Potassium, chloride and sulphate ions were the most predominant with concentrations of $2.25,1.47$ and $0.83 \mathrm{~g} \mathrm{~L}^{-1}$, respectively, thus accounting for almost $83 \%$ of the total ions. The final product, obtained after distillation, had experienced a reduction in the ions concentration of approximately $80 \%$ decreasing the total ions concentrations to about $1.1 \mathrm{~g} \mathrm{~L}^{-1}$. Therefore, the total percentage of impurities was only $0.1 \%$ (considering that final LA concentration was $930 \mathrm{~g} \mathrm{~L}^{-1}$ ). Finally, the enantiomeric purity of the product was $95.5 \%$ of L-LA. 


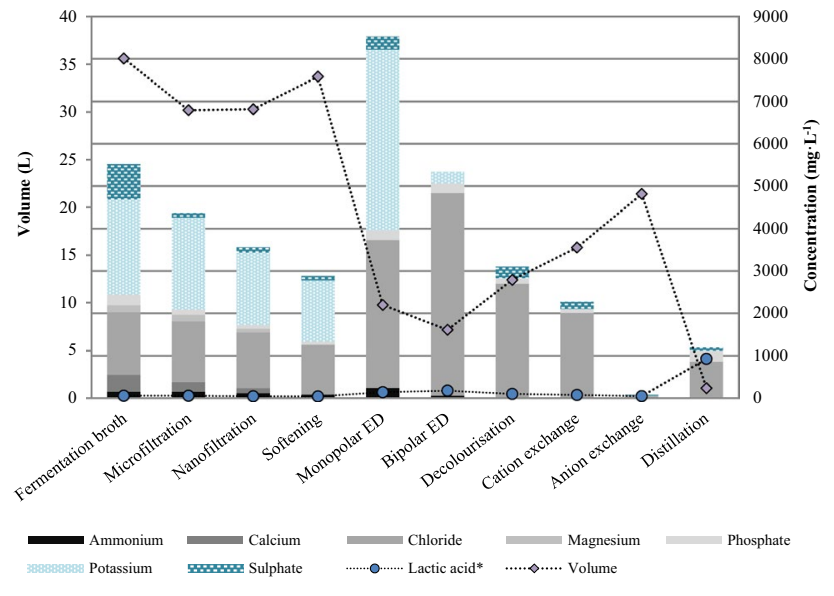

Fig. 6 Variation in the volume and concentration of ions and LA after the downstream steps. LA concentrations are given in $\mathrm{g} \mathrm{L}^{-1}$

\section{Discussion}

As expected, considerable variations in the amount of released sugars were observed between hydrolysates obtained from different OFMSW samples. Those differences were likely due to the growth of LAB on the material before hydrolysis even started. LA was detected in all samples with higher concentrations observed for samples obtained during warmer months. This phenomenon is decisive in the LA optical purity of the final product as described by López-Gómez et al. [23]. Hydrolysates containing a high concentration of racemic LA yield poor optical purities, a crucial issue that would limit the application of the product. Additionally, as shown in "Substrate and Hydrolysis" section, hydrolysates which contained a higher initial LA concentration showed significantly longer fermentation times. Nevertheless, if the application of LA does not require high enantiomeric purities, the quality of the hydrolysate would only impact the fermentation step rates, which perhaps is not a significant issue. In conclusion, unless some measures to remove D-LA are taken, the final application of the process will be dictated by the substrate itself. Further work could be carried out to investigate in detail the effect that seasons have in the LA formation pre-hydrolysis. Most likely, a reduction in OFMSW collection and storage times would benefit the process.

As previously shown by López-Gómez et al. [8], it was apparent that the fermentation step is in general not an issue. B. coagulans, without the addition of any external source of nutrients, was able to growth in the hydrolysate and consume all the glucose, achieving conversions of $65 \%$. Even better were the cases when low initial LA was present in the hydrolysate in which the fermentation occurred more rapidly. An important advantage of the process is the similar working temperatures for both the hydrolysis $\left(50^{\circ} \mathrm{C}\right)$ and fermentation steps $\left(52{ }^{\circ} \mathrm{C}\right)$. This small temperature difference means that the fermentations could start in the same vessel, without the need of large quantities of heating or cooling energy involved which at the large scale becomes a more significant feature of the process. Additionally, this high temperature reduces microbial contamination issues making the process even more attractive.

Clearly, the downstream is still a very challenging step. The total losses accounted for almost 55\% of the total LA produced which greatly restricts the potential of the process. Nonetheless, the experiment revealed some important aspects about the purification. It is necessary to search for alternatives to improve the microfiltration and nanofiltration steps. These two steps accounted for up to $60 \%$ of the total losses of the process. Naturally, even slight improvements in these stages of the downstream could have a great impact in the final product recovery. On the positive side, even though OFMSW is a very complex material, the downstream proved to be successful in the removal of ions with a final concentration of impurities of only $0.1 \%$. Furthermore, a LA final concentration of $930 \mathrm{~g} \mathrm{~L}^{-1}$ was achieved by the end of the process. Because the microfiltration is used to remove solids and the nanofiltration is used to remove sugars and proteins, it is conceivable to envisage improvements in the process which would not be affected by the quality of the hydrolysate.

The yield from OFMSW to LA until the end of the fermentation was $0.22 \mathrm{~g}_{\mathrm{LA}} \mathrm{g}_{\text {dryOFMSW }}^{-1}$ a slightly lower value to the one reported before $\left(0.23 \mathrm{~g}_{\mathrm{LA}} \mathrm{g}_{\text {dryOFMSW }}^{-1}\right)$ [8]. Overall, the yield of the process including the purification was 0.11 $\mathrm{g}_{\mathrm{LA}} \mathrm{g}_{\text {dryOFMSW}}^{-1}$

\section{Conclusion}

Experimental results showed that variations in the concentrations of sugars and LA are observed from batch to batch of OFMSW hydrolysates. More specifically, LA can reach high concentrations even before the substrates are hydrolysed, limiting the potential applications of the final product due to low enantiomeric purities. In general, fermentation of the hydrolysate is not an issue and the addition of extra nutrients is not necessary. Downstream is still a challenging stage of the process with the most significant LA losses observed during the micro- and nanofiltrations. Overall the process, a conversion of $10 \%$ from OFMSW substrate (dry basis) to LA was achieved.

Acknowledgements Open Access funding provided by Projekt DEAL. Results presented here by authors have been carried out in the framework of PERCAL project. "This project has received funding from the Bio Based Industries Joint Undertaking under the European Union's Horizon 2020 research and innovation programme under Grant Agreement No. 745828". The authors would like to thank Dr. Marcos 
Latorre-Sánchez and Mrs. Caterina Coll-Lozano from IMECAL SA (L'Alcúdia, Spain) for providing the raw OMFSW for the experiments described in this article.

Open Access This article is licensed under a Creative Commons Attribution 4.0 International License, which permits use, sharing, adaptation, distribution and reproduction in any medium or format, as long as you give appropriate credit to the original author(s) and the source, provide a link to the Creative Commons licence, and indicate if changes were made. The images or other third party material in this article are included in the article's Creative Commons licence, unless indicated otherwise in a credit line to the material. If material is not included in the article's Creative Commons licence and your intended use is not permitted by statutory regulation or exceeds the permitted use, you will need to obtain permission directly from the copyright holder. To view a copy of this licence, visit http://creativecommons.org/licenses/by/4.0/.

\section{References}

1. Yang, Y., Heaven, S., Venetsaneas, N., Banks, C.J., Bridgwater, A.V.: Slow pyrolysis of organic fraction of municipal solid waste (OFMSW): characterisation of products and screening of the aqueous liquid product for anaerobic digestion. Appl. Energy. 213, 158-168 (2018). https://doi.org/10.1016/j.apenergy.2018.01.018

2. Burnley, S., Phillips, R., Coleman, T., Rampling, T.: Energy implications of the thermal recovery of biodegradable municipal waste materials in the United Kingdom. Waste Manag. 31, 1949-1959 (2011)

3. Grosso, M., Motta, A., Rigamonti, L.: Efficiency of energy recovery from waste incineration, in the light of the new Waste Framework Directive. Waste Manag. 30, 1238-1243 (2010). https://doi. org/10.1016/j.wasman.2010.02.036

4. Bonk, F., Chaturvedi, T., Torres, A.I., Schmidt, J.E., Thomsen, M.H., Stephanopoulos, G.: Exploring opportunities for the production of chemicals from municipal solid wastes within the framework of a biorefinery. In: 12th International Symposium on Process Systems Engineering and 25th European Symposium on Computer Aided Chemical Engineering. pp. 2123-2128. Elsevier (2015)

5. Abudi, Z.N., Hu, Z., Sun, N., Xiao, B., Rajaa, N., Liu, C., Guo, D.: Batch anaerobic co-digestion of OFMSW (organic fraction of municipal solid waste), TWAS (thickened waste activated sludge) and RS (rice straw): influence of TWAS and RS pretreatment and mixing ratio. Energy. 107, 131-140 (2016). https://doi. org/10.1016/j.energy.2016.03.141

6. Matsakas, L., Gao, Q., Jansson, S., Rova, U., Christakopoulos, P.: Green conversion of municipal solid wastes into fuels and chemicals. Electron. J. Biotechnol. 26, 69-83 (2017). https://doi. org/10.1016/j.ejbt.2017.01.004

7. Silva, F.C., Serafim, L.S., Nadais, H., Arroja, L., Capela, I.: Acidogenic fermentation towards valorisation of organic waste streams into volatile fatty acids. Chem. Biochem. Eng. Q. 27, 467-476 (2013)

8. López-Gómez, J.P., Latorre-Sánchez, M., Unger, P., Schneider, R., Coll Lozano, C., Venus, J., Lozano, C.C., Venus, J.: Assessing the organic fraction of municipal solid wastes for the production of lactic acid. Biochem. Eng. J. 150, 107251 (2019). https://doi. org/10.1016/j.bej.2019.107251

9. Dreschke, G., Probst, M., Walter, A., Pümpel, T., Walde, J., Insam, H.: Lactic acid and methane: improved exploitation of biowaste potential. Bioresour. Technol. 176, 47-55 (2015). https://doi. org/10.1016/j.biortech.2014.10.136

10. Probst, M., Walde, J., Pümpel, T., Wagner, A.O., Insam, H.: A closed loop for municipal organic solid waste by lactic acid fermentation. Bioresour. Technol. 175, 142-151 (2015). https://doi. org/10.1016/j.biortech.2014.10.034
11. Probst, M., Walde, J., Pümpel, T., Wagner, A.O., Schneider, I., Insam, H.: Lactic acid fermentation within a cascading approach for biowaste treatment. Appl. Microbiol. Biotechnol. 99, 30293040 (2015). https://doi.org/10.1007/s00253-015-6414-7

12. Campuzano, R., González-Martínez, S.: Characteristics of the organic fraction of municipal solid waste and methane production: a review. Waste Manag. 54, 3-12 (2016). https://doi.org/10.1016/j. wasman.2016.05.016

13. Paritosh, K., Yadav, M., Mathur, S., Balan, V., Liao, W., Pareek, N., Vivekanand, V.: Organic fraction of municipal solid waste: overview of treatment methodologies to enhance anaerobic biodegradability. Front. Energy Res. (2018). https://doi.org/10.3389/ fenrg.2018.00075

14. Probst, M., Fritschi, A., Wagner, A., Insam, H.: Biowaste: a Lactobacillus habitat and lactic acid fermentation substrate. Bioresour. Technol. 143, 647-652 (2013). https://doi.org/10.1016/j.biort ech.2013.06.022

15. de Oliveira, R.A., Alexandri, M., Komesu, A., Venus, J., Vaz Rossell, C.E., Maciel Filho, R.: Current advances in separation and purification of second-generation lactic acid. Sep. Purif. Rev. (2019). https://doi.org/10.1080/15422119.2019.1590412

16. Neu, A.-K., Pleissner, D., Mehlmann, K., Schneider, R., PuertaQuintero, G.I., Venus, J.: Fermentative utilization of coffee mucilage using Bacillus coagulans and investigation of down-stream processing of fermentation broth for optically pure $1(+)$-lactic acid production. Bioresour. Technol. 211, 398-405 (2016). https://doi. org/10.1016/j.biortech.2016.03.122

17. Alexandri, M., Neu, A.-K.K., Schneider, R., López-Gómez, J.P., Venus, J.: Evaluation of various Bacillus coagulans isolates for the production of high purity L-lactic acid using defatted rice bran hydrolysates. Int. J. Food Sci. Technol. 54, 1321-1329 (2018). https://doi.org/10.1111/ijfs.14086

18. Castro-Aguirre, E., Iñiguez-Franco, F., Samsudin, H., Fang, X., Auras, R.: Poly(lactic acid: mass production, processing, industrial applications, and end of life. Adv. Drug Deliv. Rev. 107, 333-366 (2016). https://doi.org/10.1016/j.addr.2016.03.010

19. Pleissner, D., Schneider, R., Venus, J., Koch, T.: Separation of lactic acid and recovery of salt-ions from fermentation broth. J. Chem. Technol. Biotechnol. 92, 504-511 (2017). https://doi. org/10.1002/jctb.5023

20. Komesu, A., WolfMaciel, M.R., MacielFilho, R.: Separation and purification technologies for lactic acid: a brief review. BioResources. 12, 1-4 (2017). https://doi.org/10.15376/biore s.12.3.6885-6901

21. Olszewska-Widdrat, A., Alexandri, M., López-Gómez, J.P., Schneider, R., Mandl, M., Venus, J.: Production and purification of L-lactic acid in lab and pilot scales using sweet sorghum juice. Fermentation. 5, 36 (2019). https://doi.org/10.3390/fermentati on5020036

22. Pleissner, D., Neu, A.-K., Mehlmann, K., Schneider, R., PuertaQuintero, G.I., Venus, J.: Fermentative lactic acid production from coffee pulp hydrolysate using Bacillus coagulans at laboratory and pilot scales. Bioresour. Technol. 218, 167-173 (2016). https://doi. org/10.1016/j.biortech.2016.06.078

23. López-Gómez, J.P., Alexandri, M., Schneider, R., LatorreSánchez, M., Coll Lozano, C., Venus, J.: Organic fraction of municipal solid waste for the production of L-lactic acid with high optical purity. J. Clean. Prod. 247, 119165 (2020). https://doi. org/10.1016/j.jclepro.2019.119165

Publisher's Note Springer Nature remains neutral with regard to jurisdictional claims in published maps and institutional affiliations. 